Butterworth \& Co. Ltd. 1959. Price 47s. 6d. (Interleaved Edition 67s. 6d.).

This book is planned to provide the house surgeon, the Fellowship candidate and the practitioner with a concise account of orthopaedic and fracture surgery. It does this very well. The author covers his subject in three main sections-general aspects of orthopaedic surgery such as infective and neoplastic disease; special considerations applicable to the various regions of the body and finally an account of fractures and dislocations. In each of these sections the writing is clear and concise and the presentation is well planned. There is practically no waste of space by repetition of useless but time-honoured textbook material, and it is pleasant to find the author replacing the usual tiresome jargon by words which mean something to every reader: This is essentially a practical book which helps the student to make a rational approach to the various problems of orthopaedic surgery and guides him to a systematic elucidation of these problems. It does more than this; it introduces an unusual and refreshingly new mode of thought and it also helps the reader to a wider knowledge by giving numerous and well-selected references for further study. It is not perhaps going too far to suggest that not only the occasional practitioner but also the 'expert' may derive profit from reading it.

Of course, in a book of this type there is bound to be a good deal of dogmatism, but the reader has the assurance that the author, with his wide experience in orthopaedic work, is unlikely to recommend a course the results of which he has not personally observed. The touch of dogmatism will be welcomed by the examination candidate and it is not out of place for the less-experienced practitioner, who has to make up his mind on the basis of his own observations and of guidance from one of more experience. The critical reader may object to the occasional deviation from orthodox English and to the use of unusual words such as 'flailness.' It must be said though that these unusual words serve well to convey the author's meaning. Others may comment on the absence of illustrations. Mr. Apley has no doubt weighed the possible advantages of these against the disadvantage of increased size and has, in the opinion of the reviewer, made the right choice. A book which is going to be handled a great deal might perhaps have a tougher binding, but clearly this is something which could be altered in the light of experience.

The book can be strongly recommended to the group of practitioners for whom it is intended; it may also serve as a model for other more detailed works.

\section{THE PROCESS OF AGEING IN THE NERVOUS SYSTEM}

By 32 contributors. Edited by JAMES E. BIRREN, Henry A. Imus and William F. Windle. Pp. 224. Oxford: Blackwell Scientific Publications. I 959 . 52s. $6 \mathrm{~d}$.

This volume of the Symposia in Neuroanatomical
Sciences, from the National Institutes of Health, Bethesda, is a compilation of I I short papers interlarded with four round-table discussions. The experts present were chiefly anatomists but neurophysiology, neuropathology, psychiatry and related disciplines were well represented. The reader soon discovers that these deliberations fully expose the wide gaps in our fundamental knowledge of the subject, and such concrete facts as were advanced in fact do little to bridge these deficits. More questions have been asked than answered, and it may well be felt that this symposium was of value if only because it robbed us of the easy assumption that the decline of the brain in old age is to be explained simply in terms of a gradual loss of cortical neurones and the formation of senile plaques.

The careful observation of the ageing laboratory animal, such as the guinea-pig, leads to the conclusion that the only detectable microscopic change is the accumulation in neurones of lipofuscin. Yet again it was clear that the significance of this pigment is obscure and it has not been established that its presence is detrimental to function. Possibly, as others pointed out, there is more to be gained by the assessment of numerical changes in the neuronal synapses since their depletion might have a bearing upon the slowing down of reaction times in the aged.

The extraordinary difficulties of the ageing problem are revealed (p. I00) where members of the conference are asked to consider whether in fact the nervous system does age, or whether the features of senescence are governed by factors other than age itself! If the reader is thus left with an uncomfortable void at least he may be grateful to these researchers who, attacking the problem from diverse angles, have discussed the difficulties with so much honesty.

\section{THE INNERVATION OF MUSCLE A Biopsy Study}

By C. Cö̈rs and A. L. Woolf. Pp. 149. Oxford: Blackwell Scientific Publications. I959. 42s.

A new chapter in the study of muscle pathology has been opened by the technique of intravital staining of the motor nerve-endings with methylene blue, perfected by Coërs in the present decade and ably pursued by Woolf at Smethwick. In this monograph they present their observations on a series of $45^{\circ}$ biopsies taken from normal and abnormal subjects. After giving practical details of the techniques employed (cholinesterase and Bielschowsky preparations were also studied) they describe the normal topography and histology of the intramuscular nerve-endings. The range of variation thus encountered must be mastered to appreciate the succeeding sections on the general and special pathology of these structures.

Though no specific abnormality of diagnostic significance has so far emerged, the authors are satisfied that there are distinctive patterns of ter- 